\title{
LA FABULA DE LA GOLONDRINA DE GRECIA A LA INDIA Y LA EDAD MEDIA
}

\begin{abstract}
A study of the fourteen versions known to us of the fable "The Swallow and the Birds:. The richness of the tradition of this fable allows to follow its evolution from Demetrius Phalereus onwards through Classical, Medieval and Indian literatures. It is possible to point out four choliambic versions directly derived in III B.C. from Demetrius together with another old version maybe in prose, maybe in verse. The four choliambic versions produced the prosifications preserved in Coll. Augustana (39a and b H.), in P. Rylands 493 and in P. Mich. 457 plus P. Yale inv. 1158 v. Some traces of the fifth version can be found in Romulus 77 and Tanträkhyäyika III 11. Secondary derivations in Babrius, Phaedrus and in the Middle Ages are also studied. The study as a whole tries to show how can be reconstructed the evolution of a fable in its form and contents as well as its temporal and geographical dispersion.
\end{abstract}

\section{Planteamiento general}

En un artículo publicado en esta revista en 1952 sobre la importante colección de fábulas del P. Rylands 493 ' estudié, entre otras, la fábula de la lechuza y los pájaros que en dicho papiro aparece en estado fragmentario. Logré, por primer vez, la identificación de esta fábula con la de "La golondrina y los pájaros», conocida en diversas versiones, sobre todo las de la Augustana 39a y 39b, identificación que había escapado al editor C. H. Roberts ${ }^{2}$. Varía el ave, pero hay entre las dos fábulas una coincidencia lo suficientemente grande como para postular que son dos variantes de un misma fábula original: conclusión en que me siguieron más tarde B. E. Perry ${ }^{3}$ y M. Nфjgaard ${ }^{4}$.

\footnotetext{
' El Papiro Rylands 493 y la tradición fabulística antigua», EMERITA 20, 1952, pp. 337-388.

${ }^{2}$ Cf. su edición en Catalogue of the Greek and Latin Papiry in the John Rylands Library, III, Manchester 1938, p. 119 ss. También *A Fable Recovered*. JRS 47, 1957, pp. 124-125.

3 «Demetrius of Phalerum and the Aesopic Fables», TAPHA 93, 1962, p. 315 ss..

${ }^{4}$ La Fable antique I, Copenhague 1964, p. 190.
} 
Las variantes conocidas de esta fábula original, sea con la lechuza, sea con la golondrina como personaje central, son numerosas. Ello me llevó a intentar en aquella ocasión trazar un stemma de la ramificación de la fábula. En este stemma entraban, a más de las tres versiones ya mencionadas, dos de Dión Crisóstomo (XII 7 ss y LXXII 14 ss.) con la lechuza como protagonista, versiones que derivé, creo que correctamente, de la del P. Rylands, llamada por mí $\mathbf{R}$ : aunque es discutible si derivan directamente o, como postulé en aquella ocasión, a través de versiones intermedias perdidas. $\mathrm{Y}$ entraban también otras versiones a base de la golondrina, sobre todo una de la paráfrasis Bodleiana ( 350 Ch. = $164 \mathrm{Cr}$.), que se considera derivada de Babrio, y la de Rómulo 24, que se considera derivada de Fedro. En mi artículo yo entendía la versión de Babrio como estrechamente emparentada con la primera de la Augustana (39a) y la de Fedro como contaminada de esta tradición y la derivada del P. Rylands: cosa esta última que considero hoy que debe interpretarse en sentido contrario. Tampoco sostendría yo hoy la hipótesis de que la segunda versión de la Augustana, la de 39b, es muy tardía y deriva de Fedro.

La fábula de la golondrina ha continuado interesándome y creo que ha llegado el momento de someterla a un nuevo examen. Ello por una serie de razones:

a) El descubrimiento de restos métricos en las fábulas griegas en prosa y de que estos restos remontan a versiones métricas del s. III a. C. nos suministra un instrumento absolutamente valioso para reconstruir la forma antigua de las fábulas e investigar sus derivaciones y ramificaciones. Este descubrimiento remonta a un artículo publicado en esta misma revista en 1969-70 s. Precisamente desde el primer momento me resultó claro que las dos versiones de la Augustana y la del P. Rylands presentan restos de verso coliámbico ${ }^{6}$.

b) La investigación de mi Historia de la Fábula Greco-Latina (Madrid 1979) sobre la evolución de la tradición fabulística griega (historia de las versificaciones y prosificaciones, entrada de elementos cínicos y otros, influencia de la fábula griega en la India, etc.) es susceptible de iluminar puntos oscuros de la evolución de la fábula que nos ocupa.

c) Se añade que, hoy, podemos of recer un material más abundante que en la época de mi primer artículo e, incluso, de mi libro. Además de

\footnotetext{
3.La tradición fabulistica griega y sus modelos métricos*. EMErıTA 37, 1969, pp. 235-315 y 38, 1970, pp. I-52. Ha sido profundizado en mi Historia de la Fíbula Greco-Latina. I. Madrid, 1979, sobre todo pp. 71 ss. y 551 ss.

•Cf. .La tradición...* 1969, pp. 248, 313 y 1970, p. 45; Historia..., pp. 538 y 603 ss.
} 
las versiones principales de la fábula a que antes hemos hecho referencia, hoy he de señalar, sobre todo: la fábula griega de P. Mich. $457+P$. Yale inv. 1158 v., ya citada en Historia... pero que sólo ahora veo que contiene también ella restos de verso; una segunda fábula de Rómulo, la 77, «Los pájaros y el pajarero»; y la fábula de Tranträkhyāyika III 11, «El cisne salvador» ?. Hay todavía más derivados en la tradición latina medieval; luego hablaré de ellos.

Es todo esto lo que me mueve a volver a estudiar el tema de èsta compleja fábula, sobre cuyo stemma había propuesto algunas modificaciones en Historia..., p. 603 ss. Pero pienso que se puede ir mucho más lejos. Entre otras cosas, la restitución del verso originario (ahora de cuatro fábulas griegas, apaŕte de la dependiente de Babrio) nos permite avanzar más: lo restituyo ahora en forma más completa que antes.

Antes de seguir, con todo, conviene decir algunas palabras sobre el tema de la fábula objeto de este artículo, con destino al lector que no tenga muy presente su variación temática.

Se trata siempre en fecha antigua del tema de por qué la lechuza, en un caso, y la golondrina, en el otro, habitan en las casas y no en los árboles. La lechuza o la golondrina (o un ave innominada en Rómulo 77 o el cisne en la fábula india) avisan a los pájaros del peligro que representan para ellos los robles que crían muérdago (del que se fabrica la liga), unas veces; o el lino de que se hacen redes, otras (con una variante local en la fábula india). Los pájaros deben impedir que crezcan esos robles o ese lino o, si no, suplicar a los hombres y refugiarse en sus casas (este último tema falta en algunas fábulas derivadas). Pero ellos no lo hacen y el resultado es que son capturados mientras que la lechuza o la golondrina se salvan y viven con los hombres.

Se trata de fábulas etiológicas que explican por qué ciertas aves viven con los hombres y son respetadas por ellos, por qué otras viven en los árboles y son cazadas. Por otra parte, cuando interviene la lechuza (en P. Rylands y sus derivados), hay una segunda etiología: por qué los pájaros, de día, revolotean en torno a la lechuza y ella gime (ya es demasiado tarde para ayudar a las aves, después que no hicieron caso de su consejo). El problema es saber cuál es lo más antiguo: si la fábula basada en la lechuza o en la golondrina (naturalmente, si es que ambas tienen el mismo origen).

Un análisis temático de las diversas fábulas nos llevaría a descompo-

\footnotetext{
'Cf. J. Hertel, Tanträhhyäyika, Leipzig y Berlín 1909, dos vols. El Tanträkhyäyika representa, como $⿻$ sabe, la más antigua versión del Pañcatantra.
} 
nerlas en los siguientes elementos, que utilizaremos para la descripción formal:

AVE: $\mathrm{A}=$ golondrina, $\mathrm{B}=$ lechuza, $\mathrm{C}=$ otra ave, $\mathrm{D}=$ pájaros, $\mathrm{E}=$ ruiseñor.

TRAMPA: $a=$ liga, $b=$ lino ( $b 1$ usado en redes, $b 2$ de otra forma), $c=$ otras.

ETIOLOGIA: $\mathrm{X}=$ salvación del ave protagonista, $\mathrm{Y}=$ admiración por la misma, $\mathrm{Z}=$ otras.

\section{LAS CUATRO FÁbULAS CON VERSO ANTIGUO}

Todo este planteamiento nos permite, creo, avanzar en el análisis de las diversas fábulas, para estudiar luego sus interrelaciones. Ahora bien, creo que hoy debemos comenzar por aquellas fábulas que conservan restos del verso antiguo. Puesto que se trata de versos coliámbicos (mezclados, a veces, con trímetros yámbicos) que he fechado, pienso que en forma definitiva, en el s. III a. C., resulta claro que se trata de versificaciones diversas de fecha antigua, en conexión con la apropiación de la fábula por los cínicos. Puede haber, ciertamente, derivación directa en todos los casos de una misma fábula en prosa de Demetrio; o de dos o más fabulas del mismo; o puede haber derivaciones prosaicas intermedias entre Demetrio y el verso, aunque esto me resulta hoy sumamente inverosímil, disuena de lo que sabemos sobre la historia de la fábula. En cambio, que de una fábula en prosa salgan dos o más en verso, es normal.

Pero antes de ir a este tema hemos de presentar los datos relativos a las cuatro fábulas en cuestión (cuyas prosificaciones pueden ser, ciertamente, de fechas diversas, más o menos tardías y más o menos alteradas luego). Datos, de un lado, métricos, que se resumen en una conclusión: no hay coincidencias métricas, se trata de versificaciones independientes. De otro, datos de contenido. Veamos, pues, las cuatro fábulas una a una.

a) «La lechuza y los pájaros». P. Ryl. 493 (= R).

Recogemos el texto, incompleto, de esta versión, según la edición de Hausrath-Hunger (CFA I, 2, 1959, p. 188). Recordamos que el papiro se fecha en el s. I d. C., pero que esto es sólo un terminus ante quem para el origen de las fábulas que contiene; por razones léxicas las fechábamos en nuestro artículo en la primera koiné y después, por razones métricas, 
otra vez en la misma fecha (s. III a. C.). Claro está, en lo relativo al texto versificado original, no a las innovaciones (pensamos que muy escasas) del prosificador.

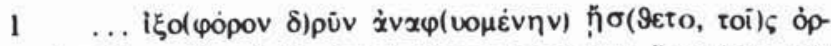

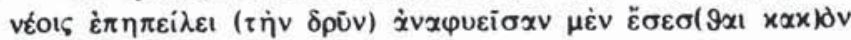

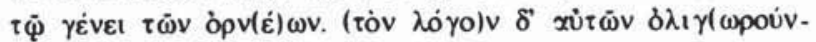

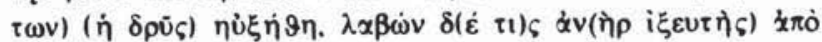

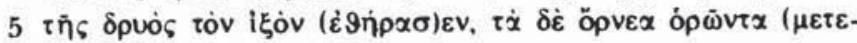

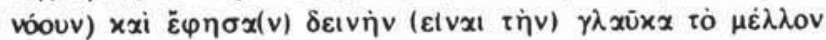

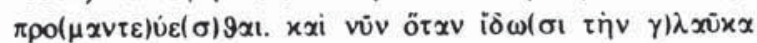

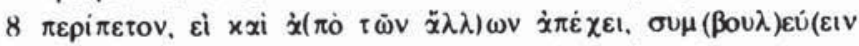
$\lambda i \sigma) \sigma(o v \tau \alpha 1)$. $\dot{\eta} \delta \dot{\varepsilon} \lambda \dot{\varepsilon} \gamma \varepsilon i^{\circ}[\pi] \dot{\omega} \pi 0 v \eta(\rho \dot{\alpha}, \alpha i \sigma \chi) u \dot{u}(v) \varepsilon \sigma 9 \varepsilon$

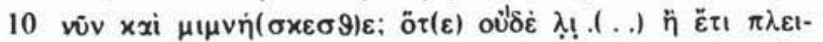

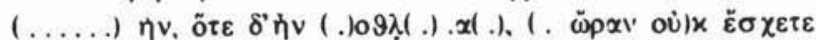

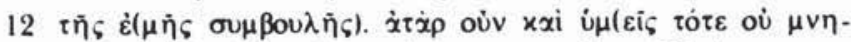

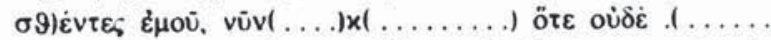

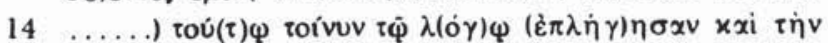

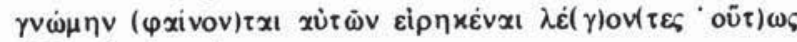

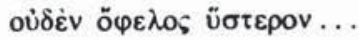

Hallamos los siguientes fragmentos métricos de trímetros y coliambos (algunos enteros o casi enteros):

1 u-u-u-u i

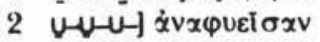

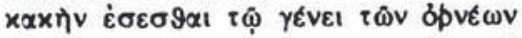

(Pap. $\check{\varepsilon} \sigma \varepsilon \sigma[\vartheta \alpha \iota \quad x \alpha x] \partial v$ )

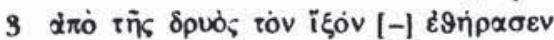

$4 u-U-U$ ]

$5 x \alpha i$ vôv ör $\alpha v i \delta \omega \sigma \imath \quad \gamma \lambda \alpha \tilde{x} \alpha \alpha \pi \varepsilon p(\pi \varepsilon \tau o v$

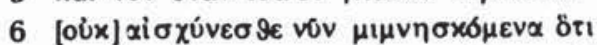

(Pap. $\left.\times \alpha \nmid \mu \iota \mu \nu \gamma \sigma \times \varepsilon \sigma 9^{\prime}\right)$

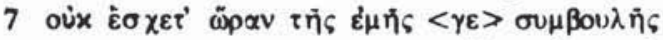

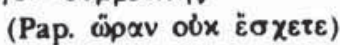

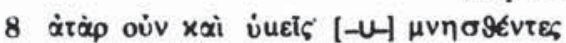

غे

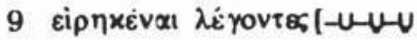

Estos son los fragmentos métricos que pueden obtenerse con mínimas modificaciones de mi texto de la fábula; de las conjeturas de la edición de Hausrath-Hunger ${ }^{8}$ podrían sacarse algunos más (toţ dpvêı

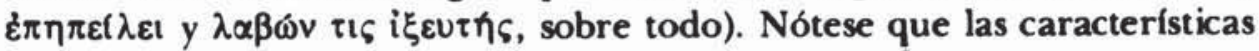
métricas en cuanto a la mezcla de coliambos y trímetros yámbicos, uso de los pies y pausas, etc., coinciden con las atribuidas en mi libro a la

\footnotetext{
Corpus fabularum Aesopicarum I 2, Teubner 1959, p. 188.
} 
fábula helenística, e igual las prosódicas (nótese sobre todo una abreviación ante vocal en tiempo fuerte del segundo pie, en 8$)^{9}$.

Pasemos ahora al contenido de la fábula. La lechuza, viendo que está a punto de nacer un roble de los que crían muérdago, da a los pájaros un consejo que se ha perdido: sin duda, arrancarlo, como en Dión Crisóstomo XII 7-9 (en adelante D. C.-A). Pero ellos desprecian el consejo, por lo que un hombre coge el muérdago y les caza (evidentemente, fabricando liga, la palabra griega i $\zeta \sigma \varsigma$ tiene ambos sentidos). Por ello, los pájaros admiran a la lechuza por su previsión del futuro y la rodean pidiéndole consejo. Pero ella les recuerda su anterior falta de atención y los pájaros reconocen que ya es demasiado tarde.

Se trata, pues, de un agón lechuza/pájaros, estando representado por el muérdago o la liga el motivo de la trampa. La etiología es doble. Explica:

a) Por qué los pájaros son cazados con la liga. Es un motivo antiguo: la fábula se refiere al momento de la creación de los robles que crían muérdago, sólo una especie de roble o $\delta \rho \tilde{\varsigma} \varsigma$, como ya hice ver ${ }^{10}$. Se trata, pues, de una fábula etiológica que explica la naturaleza de ciertos animales por los orígenes del mundo: o sea, de un tipo muy antiguo. Nótese que no se habla de que la lechuza viva en las casas, ni siquiera de que los pájaros vivan en los árboles. Pero es sin duda un motivo antiguo, del que queda una huella en D. C.-B, véase más abajo. Si no hubiera habido este tema, dificilmente se explicaría la fábula.

b) Hay, en cambio, una etiología muy explícita: por qué los pájaros se congregan de día en torno a la lechuza. Es que es un ave sabia: esto, que es un dato tradicional (relación del ave con Atenea, etc.), se explica aquí a partir de su profecía sobre el muérdago. Son dos motivos unidos bastante artificialmente, sobre todo teniendo en cuenta que las lechuzas y demás aves nocturnas sí que viven en los árboles.

Mi impresión, contraria a la de mi artículo anterior, es que antiguamente la fábula se refería a la golondrina $y$, al cambiarse ésta por la lechuza, se eliminó casi el tema de la habitación del ave y se introdujo el de su sabiduría. En D.C.-A se introdujo un nuevo tema: el porqué la lechuza se lamenta.

Sin embargo, todo esto deberá confirmarse con nuevos datos. Por lo demás, la estructura de la fábula, con un agón verbal, la derrota de una de las partes y el nuevo diálogo en que el animal vencedor da el cierre

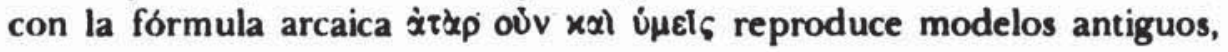

\footnotetext{
'Cf. Historia..., p. 581 ss.

10. E.l Papiro Rvlands...*, p. 361.
} 
que remontan no ya a Demetrio, sino más atrás. Para todo esto remito a mi libro.

b) «La golondrina y los pájaros». Col. Augustana 39 a (= A1).

En esta fábula, como en algunas otras, la tradición de la Augustana está dividida: dos grupos de manuscritos dan dos versiones diferentes de la fábula; en este caso (y no sólo en éste) dos versiones métricas diferentes. Estudiamos primero la de los manuscritos principales, $\mathrm{G} \mathrm{Pa}$ $\mathrm{Pb}$, cuyo texto damos a continuación por la edición de Hausrath:

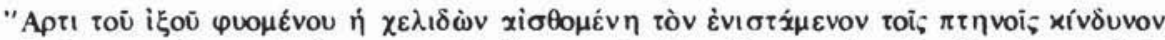

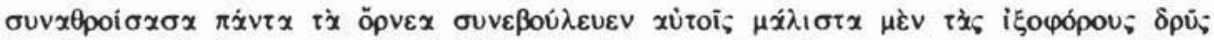

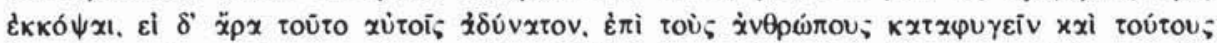

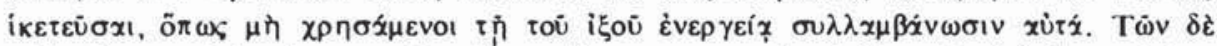

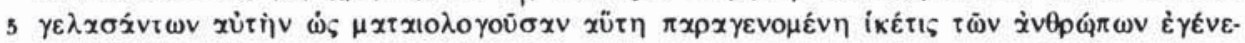

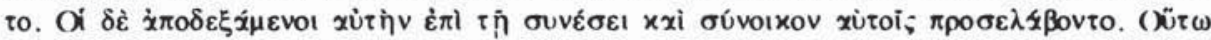

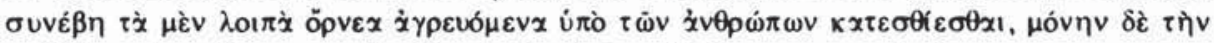

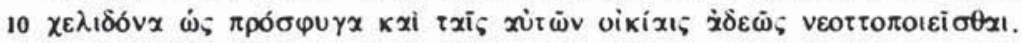

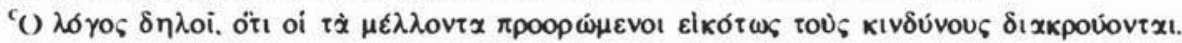

Presentamos a continuación los restos métricos, suplementando nuestras anteriores publicaciones:

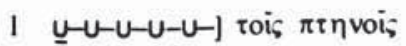

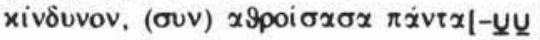

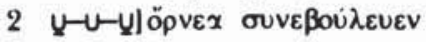

xùtol $\varsigma \mu x \dot{\lambda} \iota \sigma \tau x$

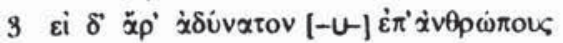

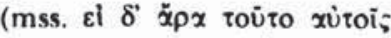

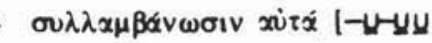

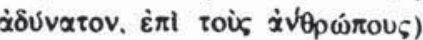

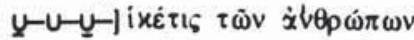

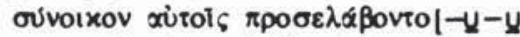

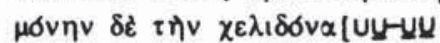

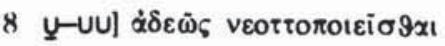

Es fácil ver que el verso es totalmente diferente y también diferente la estructura de la fábula: el agón se resuelve simplemente en acción, no hay diálogo final, ni cierre tampoco. Por otra parte, aparte de ser diferente el ave, ahora está explícita la etiología de por qué los pájaros viven en los árboles, la golondrina en la casa, como suplicante, y es respetada. Falta, por supuesto, la otra etiología.

Una primera hipótesis podría ser que nos halláramos ante fábulas diferentes desde el origen: derivadas de dos modelos diferentes de Demetrio. Esto, sin embargo, parecece poco verosímil: 
a) Existe aquí (en $\mathbf{R}$ y Al), y sólo aquí, el tema de cortar los robles criadores de muérdago en el momento en que nacen: rasgo muy arcaico, como hemos dicho. Y se deduce de él el motivo de la habitación del ave, explícito en Al, implícito en la fábula de $R$, que debe de ser derivada. (Véase más abajo). Tanto más cuanto que es la golondrina el ave que vive especialmente en las casas y es respetada como sagrada ${ }^{10}$. El consejo dado por la golondrina a los pájaros hace que sea calificada de inteligente en nuestra versión (y en su derivación en Babrio): es un rasgo que los fabulistas cínicos apreciaban mucho. En todo caso, esta inteligencia del animal es la que llevó a sustituirlo por la lechuza, considerada como ave fatídica, anunciadora de desgracias. Es éste un motivo que nada tiene que ver con el del muérdago. Pensamos, pues, que hay que invertir nuestra hipótesis: la golondrina es original en la fábula, no la lechuza. Nótese que la relación de la golondrina y las casas está reflejada en el rito; en la canción rodia de la golondrina, el ave que llega pide acogida a la mujer de la casa. En definitiva: la fábula de la lechuza se explica mal sin la de la golondrina, en la que el tema del roble y la etiología coinciden exactamente.

b) Hay coincidencias casi literales, como ya hice notar: $\mathbf{R}$ i ¿̌o

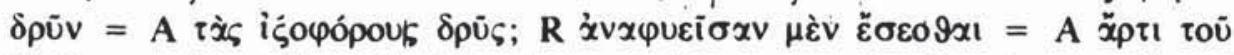

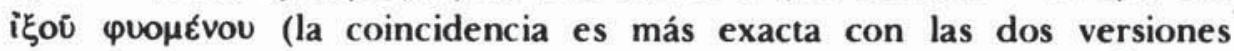

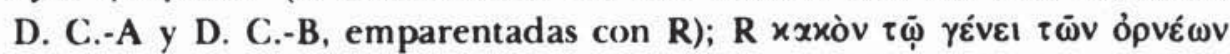

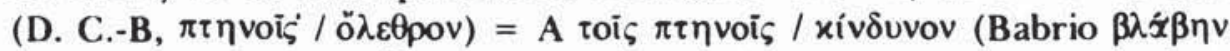

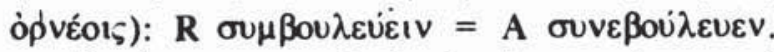

Es claro que se trata de dos versiones métricas muy diferentes y de estructura y tema también diferentes: pero hay detalles comunes. Estos aumentan en las versiones de Dión Crisóstomo, emparentadas con la de R: en D. C.-B aparece claro el tema de que los pájaros viven en los árboles, la lechuza en las casas. Esto quiere decir que nuestra prosificación $\mathbf{R}$ no transmite en forma completamente fiel la versión métrica: la derivación en Dión, sobre todo D. C.-B, conserva algunos detalles más.

c) «La golondrina y los pájaros», Col. Augustana 39 b (= A2).

Resulta claro, de todas maneras, que tanto en el caso de $\mathbf{R}$. como de Al nos hallamos ante prosificaciones de versiones métricas antiguas, relacionadas entre sí, por más que sobre el detalle de la relación alguien pueda dudar. Por lo que respecta a A2, la segunda versión de la Augustana (en los mss. Pc Pg Mb, de I; en Ia y Ib), mi hipótesis anterior

\footnotetext{
"Sobre el culto de la golondrina, cf. mi artículo - La canción rodia de la golondrina y la cerámica de Tera*, Ẹmerita 42, 1974, pp. 47-78.
} 
de que es muy reciente debe rectificarse ante la presencia clara de un verso diferente de los anteriores, pero del mismo tipo. La datación reciente es una herencia que Historia... arrastra de $* \mathrm{La}$ tradición fabulística...» y este trabajo de «El Papiro Rylands...*, anterior al descubrimiento del verso. De otra parte, la documentación más amplia de que ahora disponemos, habla en este sentido.

Texto de la fábula según Hausrath:

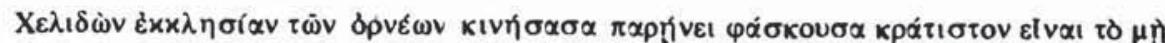

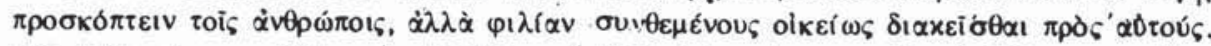

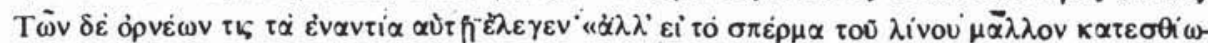

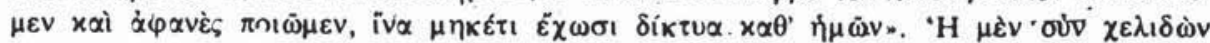

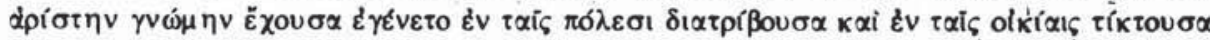

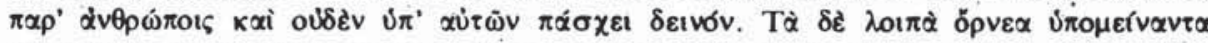

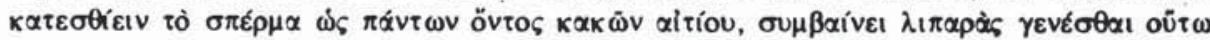

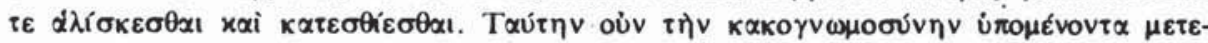

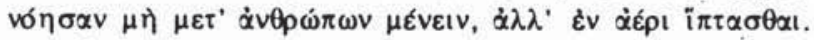

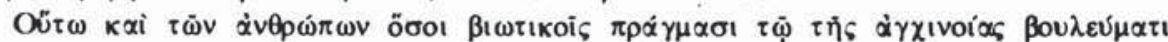
$\varepsilon \chi \rho \eta \sigma \alpha v \tau o, \dot{\alpha} \kappa i v \delta u v o เ ~ \delta เ \varepsilon \varphi v \lambda \alpha \dot{\alpha} \chi \theta \eta \sigma \alpha v$.

He aquí los restos métricos que encontramos, más extensos que en nuestros anteriores tratamientos del tema:

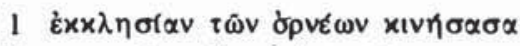

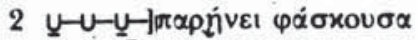

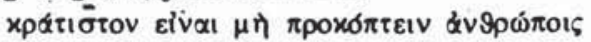

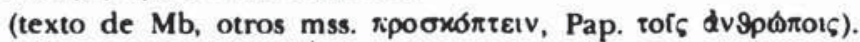

$3 \psi-U] \delta$ ]

$4 \tau \bar{\omega} v \delta$ ò

5 u-u-u-U-j to $\sigma \pi \varepsilon \rho \mu \alpha$

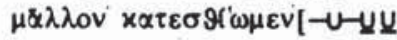

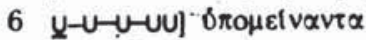

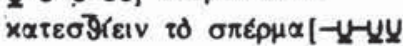

El verso es totalmente diferente del de Al y absolutamente claro; por otra parte, el tema de la fábula y aun su estructura es muy comparable a la de Al (agón verbal, sólo que en A」 en estilo indirecto ambas veces, aquí en directo la respuesta de los pájaros; conclusión de acción). La diferencia esencial es que aquí encontramos, por primera vez, el tema del lino en vez del del muérdago y la liga. Y lo encontramos de una manera extraña: mientras en otras ocasiones los pájaros no hacen caso al consejo de arrancar el lino (estrictamente paralelo al de arrancar los robles), por lo que son cazados con las redes fabricadas con el lino, aquí ni siquiera hay consejo de la golondrina más que el de irse a habitar con los hombres. Los pájaros lo rechazan y se comen la semilla del lino para que no se hagan redes: engordan y son cazados. 
O sea, de un lado, hay huellas grandes de arcaísmo: a más de las coincidencias señaladas con $\mathrm{Al}$, temas tan arcaicos como el de la asamblea de las aves y fórmulas tradicionales como la de $\varphi \imath \lambda(\alpha v$ ' ouv $9 \varepsilon \sigma 9 \alpha 1$ y

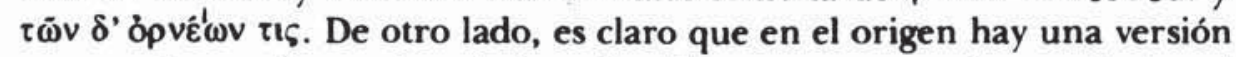
que sustituye el consejo relativo al roble por uno semejante relativo al lino y que, posteriormente, este tema es alterado en la forma reseñada. Sin duda ninguna por intervención cínica: se trata del tema del animal que, víctima de su voracidad o por cualquier otra causa, engorda y sufre las consecuencias ${ }^{12}$.

En todo caso, pienso que se trata de una fábula versificada del siglo III a. C. Para acabar de situarla hay que estudiar previamente la nueva fábula del P. Mich. 457, completada con P. Yale inv. 1158 v., publicada recientemente ${ }^{13}$.

d) «La golondrina y los pájaros», P. Mich. 457 + P. Yale inv. $1158 \mathrm{v}$. $(=\mathbf{M}-\mathbf{Y})$.

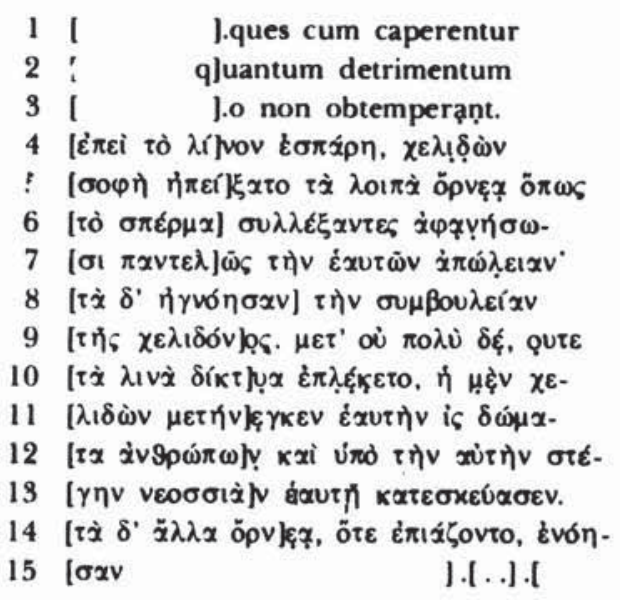

La publicación de esta versión por G. M. Parássoglou no ha despertado demasiado interés ni se ha hecho propuesta alguna, que yo sepa, sobre su inserción dentro de la tradición de la fábula de la golondrina. $\mathrm{Y}$, sin embargo, es importante porque es donde por primera vez aparece el tema del lino: de las redes de lino en que caen los pájaros. Digo por primera vez porque también en esta fábula (cuyo papiro es del siglo III d. C.) hay coliambos, es decir, es del siglo III a. C.

${ }^{12}$ Cf. H. 24 (la zorra), Horacio, Ep. I 17, 19 (los ratones). Temas semejantes en $H$. 256 (los gansos), H. 271 (la alondra), etc. Sobre el tema en general, Historia..., p. 631.

"En Stud. Pap. 13, 1974, p. 85. 
He aquí los fragmentos métricos, presentado ahora por vez. primera:

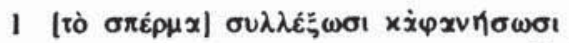

(Pap. $\sigma 0 \lambda \lambda \varepsilon \xi x v \varepsilon \varepsilon ; \dot{\alpha} \varphi x \vee \eta \sigma \omega \sigma \mathrm{l})$

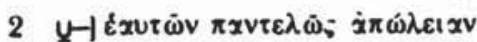

(Pap. $\pi x v \tau \varepsilon \lambda \tilde{\omega}] \leqslant \tau i) \vee \dot{\varepsilon} x \cup \tau \tilde{\omega} v \dot{\alpha}$ )

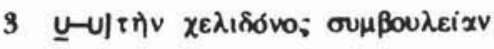

(Pap. inv o. in; $x$.)

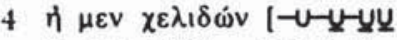

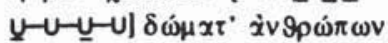

Esta cuarta versión métrica está, como hemos de ver, muy próxima a Rómulo 24, es decir, según parece más probable, a Fedro, hasta ahora aislado. Los fragmentos papiráceos griegos dejan ver solamente la siembra del lino, el consejo de la golondrina a los pájaros de hacer desaparecer la semilla, la desatención de los mismos y el tejido de redes; luego, la golondrina se refugia entre los hombres y no se ve qué es lo que, a continuación hacen los pájaros. En Rómulo las cosas son más claras: la golondrina dice primero que es mala para los pájaros la siembra del lino y aconseja luego arrancarlo; y como no tiene éxito, se refugia con los hombres y las aves caen en las redes. Véase más abajo sobre una versión aún más antigua.

Parece muy claro que esta fábula es prácticainente idéntica a $\mathrm{Al}$, con la sustitución de la trampa del muérdago por la del lino. Es notable, sin embargo, una cierta coincidencia con A2: M.-Y. $x \dot{\alpha} \varphi \alpha v \eta \sigma \omega \sigma ı=A 2 x \alpha i$ $\dot{x} \varphi x v \varepsilon \grave{\xi} \pi 01 \tilde{\omega} \mu \varepsilon v$. En las tres versiones (basándonos en Rómulo para esta rama) está el tema de la reunión o asamblea de las aves.

En definitiva. A2 parece una versificación del original prosaico de Demetrio que tiene ya en cuenta el tema del lino, o sea, M.-Y. presupone esta versión. Pero a su vez M.-Y. resulta ser una modificación de la fábula original: su tema del lino está calcado sobre el del muérdago, presente tanto en Al como en $\mathrm{R}$. Al es, a todas luces, al menos en lo temático, la continuación más fiel de Demetrio: M.-Y. es una continuación modificada, A2 otra que a su vez varía libremente, inspirándose en M.-Y. En cuanto a R, sus modificaciones (lechuza, nueva etiología) presuponen a su vez el tema que, procedente de Demetrio, se conservó en A1.

Imaginamos, pues, un original común (Demetrio) con la golondrina como protagonista, el tema del muérdago y la etiología de por qué la golondrina y los pájaros viven, respectivamente, en las casas y en los árboles. Este original se conserva, muy aproximadamente, en $\mathrm{Al}$, aunque con eliminación del estilo directo. En cambio, ha sido alterado en 
direcciones diferentes por las dos versiones $\mathbf{R}$ (lechuza y nueva etiología) y M.-Y. (lino); y también por otra versión, A2, que conoce y retoca M.-Y. (lino, con el tema cínico del animal que perece por su gula). Comienza, además, con la asamblea, eliminando el tema inicial. $O$ sea, indicando con la vertical la continuidad esencial, con la oblicua las desviaciones:

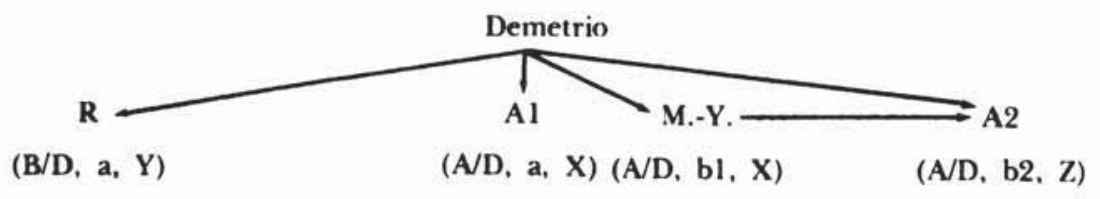

Para las siglas, véase supra, p. 188. Como se ve, no creemos ahora que haya precisión de introducir escalones intermedios (en verso o prosa) entre Demetrio y las versiones métricas presupuestas por las prosificaciones conservadas. Lo que sí hay que introducir es una diferencia entre los originales métricos de $\mathrm{R}, \mathrm{A} 1, \mathrm{M}$.-Y. y A2 y los prosificados que nos han llegado. La comparación con el resto de la tradición, que haremos a continuación, nos hará ver que ésta procede no de nuestras prosificaciones, sino de sus modelos métricos.

\section{FÁBULAS DERIVADAS DE LAS ANTERIORES}

\section{Fábulas con el tema de la lechuza}

Como hemos indicado, son sobre todo las dos de Dión Crisóstomo XII 7-9 y LXXII 14-15 que hemos llamado, respectivamente, D. C.-A y D. C.-B.

Texto de D. C.-A:

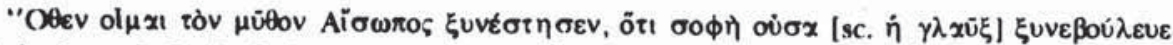

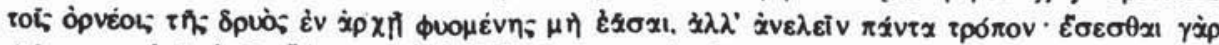

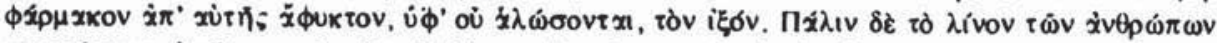

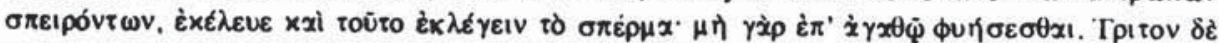

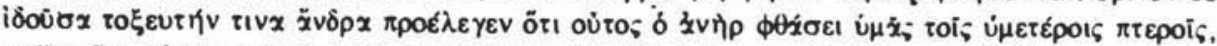

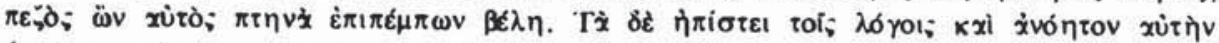

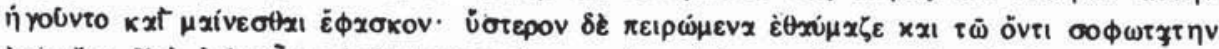

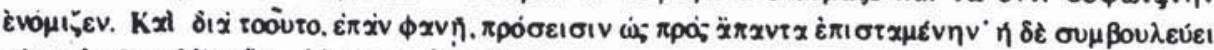

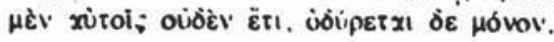


Texto de D.C.-B:

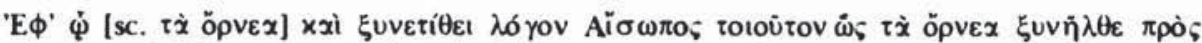

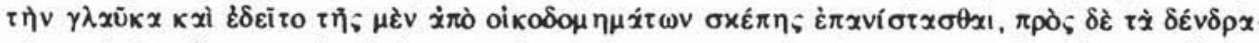

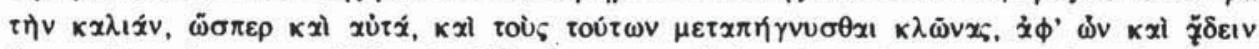

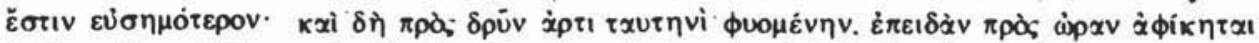

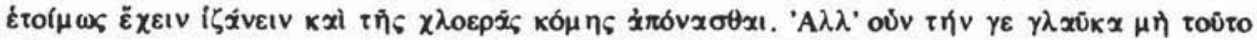

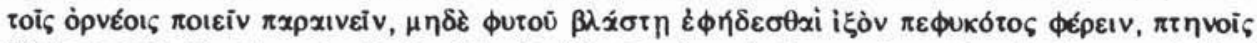

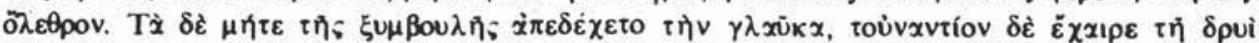

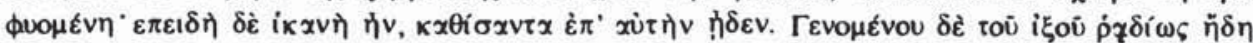

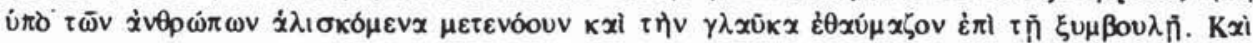

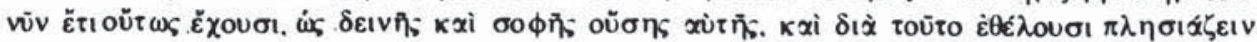

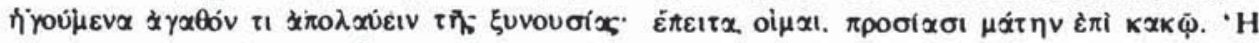

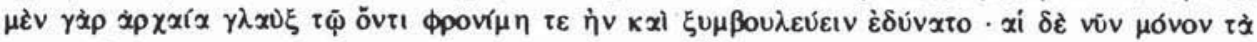

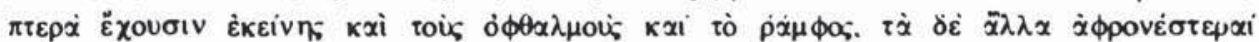

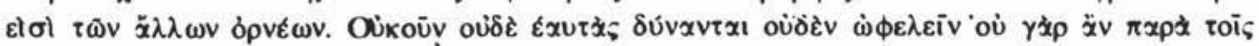

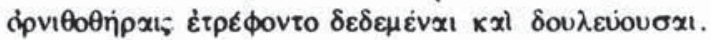

Resulta evidente que estas fábulas, que introducen el tema de la lechuza y la etiología del hecho de que los pájaros vuelen de día en torno a ella (en el caso de D. C.-A, además, de su gemido), están estrechamente emparentadas con la versión de $\mathrm{R}$. Pero desde el momento en que el tema de la lechuza se revela secundario respecto al de la golondrina - presente en tres de las cuatro versiones métricas derivadas directamente de Demetrio- la relación debe ser enfocada con un criterio diferente del de mi artículo anterior. La presencia del tema de la morada de las diferentes aves en D. C.-B, al lado de la nueva etiología, no puede comprenderse más que como un resto de la fábula antigua, eliminado en $\mathrm{R}$ y D. C.-A.

Por tanto, R y D. C.-A forman una rama independiente, caracterizada por la eliminación del motivo de la morada de las aves. Entre la versión en verso que introducía el tema de la lechuza y la etiología con ella relacionada y las dos de que nos ocupamos ahora, hay una prosificación perdida que eliminaba la otra etiología, la de la morada de las aves. Esta aparecía todavía en el verso previo, puesto que se conserva en D. C.-B.

Aparte de esto, hay variantes individuales. $R$ ha expandido seguramente la parte final, mientras que D. C.-B ha expandido la inicial (empieza con una intervención de los pájaros, siendo lo normal que se comience por una intervención del ave protagonista: así en todo el resto de la tradición). D. C.-A ha contraído la fábula, eliminando el estilo directo. Pero, además, la ha contaminado doblemente. Junto al motivo del muérdago ha hecho entrar el del lino, lo cual quiere decir que ha tenido a la vista la versión M.-Y, o en todo caso una de esta rama. 
Segunda contaminación: el tercer consejo de la golondrina a los pájaros, tomar precauciones ante un arquero que los cazará «con sus propias plumas* es a todas luces un elemento procedente de la fábula del águila que se lamenta de morir herida por la flecha hecha *con sus propias plumas»: fábula que, procedente de Esquilo 139 N., ha llegado a Demetrio, de donde derivan las versiones de la Augustana $(273 \mathrm{H}),. \mathrm{Ba}-$ brio (paráfrasis $350 \mathrm{Ch}$. $=164 \mathrm{Cr}$.), Aftonio 32 e Ignacio Diácono (Tetr. I 25).

Llegamos, pues, a un stemma parcial:

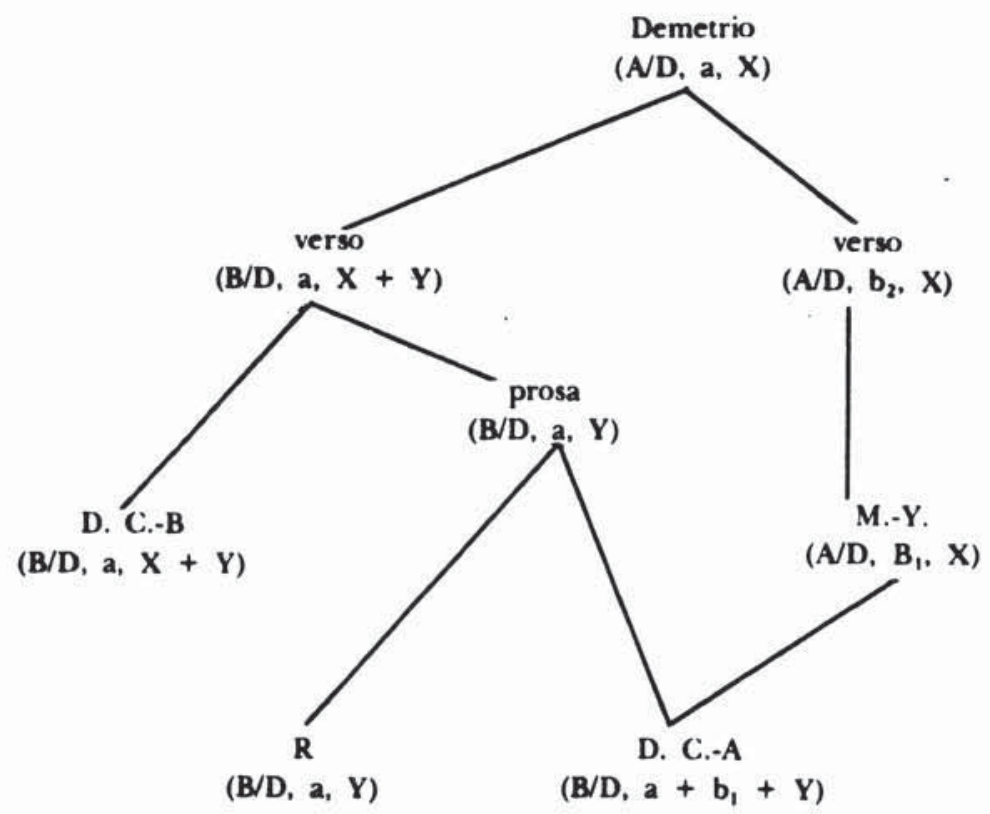

Es notable comprobar que el conocimiento de esta tradición ha llegado a la Edad Media occidental. Pues creo que de ella deriva sin duda alguna la fábula de Odón de Ceritón 55 (= 614 Perry) titulada Bubo et alia uolatilia, que transcribo a continuación:

Volatilia semel congregata inuenerunt rosam primulam et pukcherrimam, et contendebant de illa cui daretur. Et dixerunt quod aui pulcherrime. Contenderunt que esset pulcherrima. Quedam dixerunt quod sitacus; alie dixerunt quod columba, alie quod pauo. Venit bubo et dixit se. esse pulcherrimam et quod debuit habere rosam. Omnes mote sunt in risum, dicentes *Tu es auis pulcherrima per antifrasim, quoniam turpissima.- Expectauerunt de sentencia difinitiua usque mane. In nocte clare uidet bubo, et aliis auibus dormientibus, rosam furata est. Quo comperto, mane dederunt aues sentenciam, quod bubo nunquam uolaret de die nec inter alias aues habitaret et in tenebris clarius uideret, et, si die appareret, omnes aues ipsum clamore et lesione infestarent. 
Es una nueva etiología de por qué los pájaros se congregan durante el día en torno al ave nocturna. El robo de la rosa por el buho, animal feo y maligno, puede tener que ver con el tema de la serpiente y la rosa en H. 248; en todo caso, como Odón de Ceritón explica a continuación, la rosa es un símbolo cristiano (el beneficium ecclesiasticum, cura animarum). En qué variante ha llegado a un escritor del siglo XIII la antigua etiología, sustituida por él, por otra nueva, no puede saberse; pero parece claro que ha llegado a él.

\section{Las dos fábulas de Babrio}

Conservamos una fábula de Babrio, la 12, que desarrolla de una forma original el tema de la golondrina que fracasa en convencer a otras aves para que se vaya con los hombres, haciéndolo ella. Nunca ha sido traída a colación, que sepamos, en relación con la fábula de la golondrina.

Antes de ocuparnos de ella, sin embargo, vamos a recoger una fábula de la paráfrasis Bodleiana $(350 \mathrm{Ch} .=164 \mathrm{Cr}$. $)$ de que ya me ocupé en mi artículo y que, como la anterior, hay que relacionar con la versión Al (con su original en verso, mejor), es decir, con el tema de la golondrina y el muérdago. Es una fábula prosificada que deja ver en forma muy completa sus coliambos originales. Es decir, nos hallamos ante el caso conocido de una fábula en coliambos babrianos (que puede ser de Babrio o de un imitador suyo) que deriva de la tradición antigua: de una versificación de Demetrio ${ }^{14}$. He aquí, primero, el texto de la fábula, según Chambry (B1):

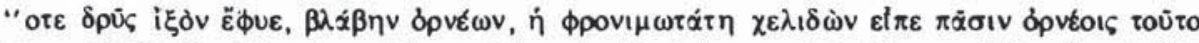

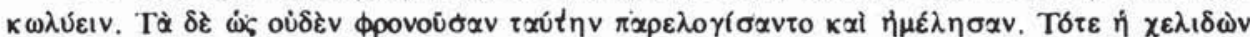

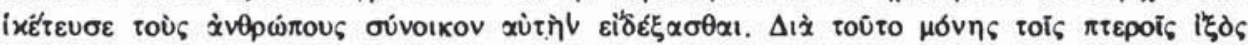
oưंठ́์

A continuación doy los restos métricos, según los veo ahora, es decir, más amplios que en publicaciones mias anteriores:

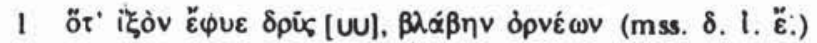

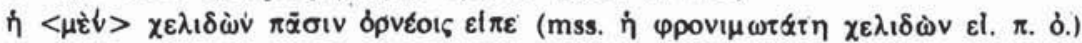

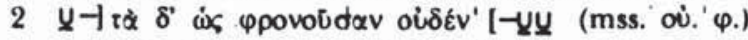

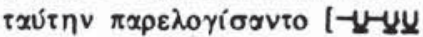

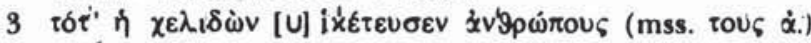

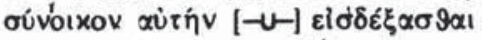

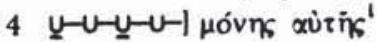

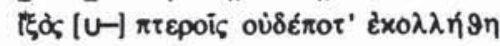

${ }^{14}$ Sobre esta derivación directa del verso y no de las prosificaciónes, véase mi Histo. ria..., p. 610 ss. 
La prosificación ha respetado, como se ve, casi íntegra una fábula de quizá 9 versos, frente a los 28 de la fábula conservada en el Atoo de Babrio (si bien Perry atetiza varios). Nada extraño hay en la existencia de dos fábulas «babrianas» (de Babrio o no, no voy a insistir aquí en este tema) derivadas de una misma fábula antigua. Derivadas con dos estilos fabulísticos muy distintos, estilos que coexisten en la colección babriana y que quizá son testimonio de dos (o más autores) dentro de la misma.

En todo caso, la fábula de que ahora nos estamos ocupando, la breve, deriva muy directamente del modelo de la Augustana 39a, es decir, de Al, sólo que cambia el final: la nueva etiología es la explicación de por qué la liga no se pega a las alas de la golondrina. Aparte de esto,

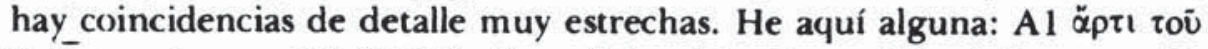

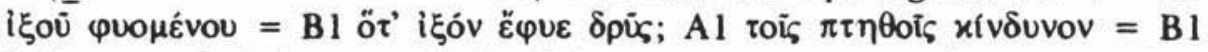

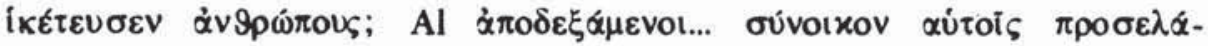

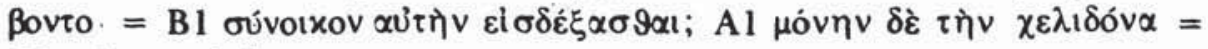
B1 uóvns aùrñs.

Que las coincidencias sean frasiológicas, pero apenas métricas (con

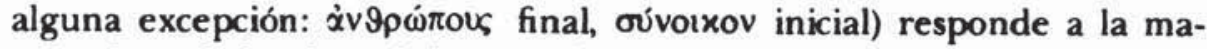
nera de trabajar de Babrio, que destroza conscientemente el verso antiguo. A su «estilo breve" responde el que falten detalles de Al (el tema de la asamblea de los pájaros, el de cortar los robles, la burla de los pájaros) que coincidencias con otras versiones demuestran ser antiguos.

He aquí, ahora, la otra fábula babriana (Babrio $12=$ B.2):

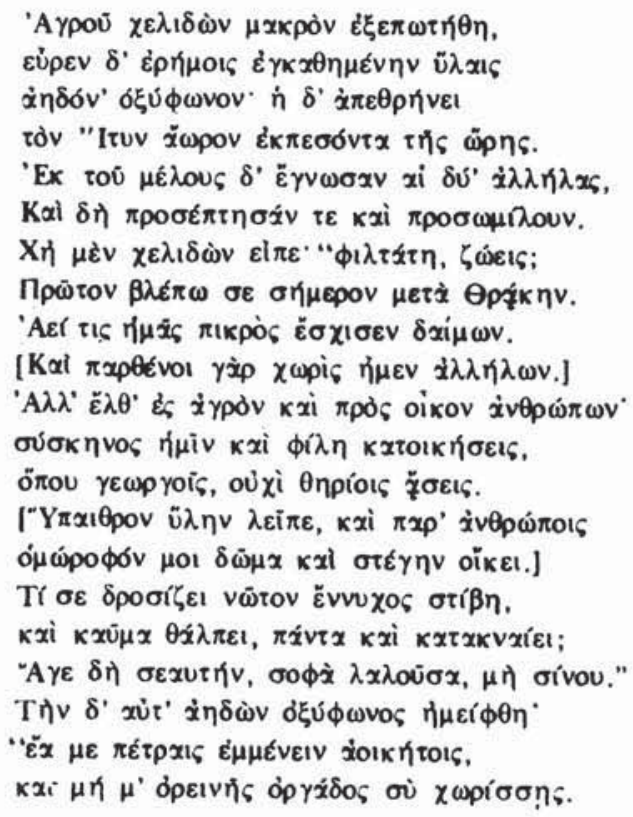




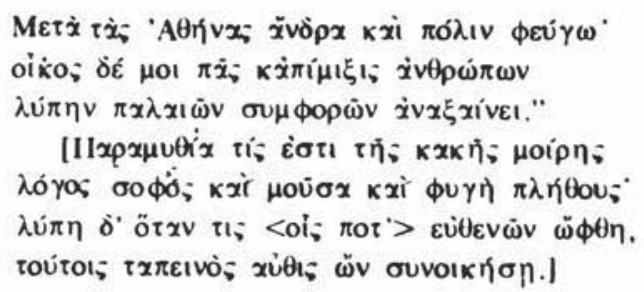

Es claro que el autor se ha tomado muy en serio la reelaboración literaria del modelo antiguo, incluido el tema. Sólo los versos 11-13, exhortación de la golondrina al ruiseñor a vivir en las casas, hace ver claramente el origen de esta fábula en la nuestra. Lo demás está cambiado: ahora quien no quiere vivir con los hombres es el ruiseñor, que recuerda la muerte de su hijo Itis. Por supuesto, el tema del muérdago ha desaparecido. O sea: la fábula ha sido tomada como base para dar una nueva variación o *continuación" del mito de Procne y Filomela.

Tenemos aquí, en suma, un nuevo stemma parcial:

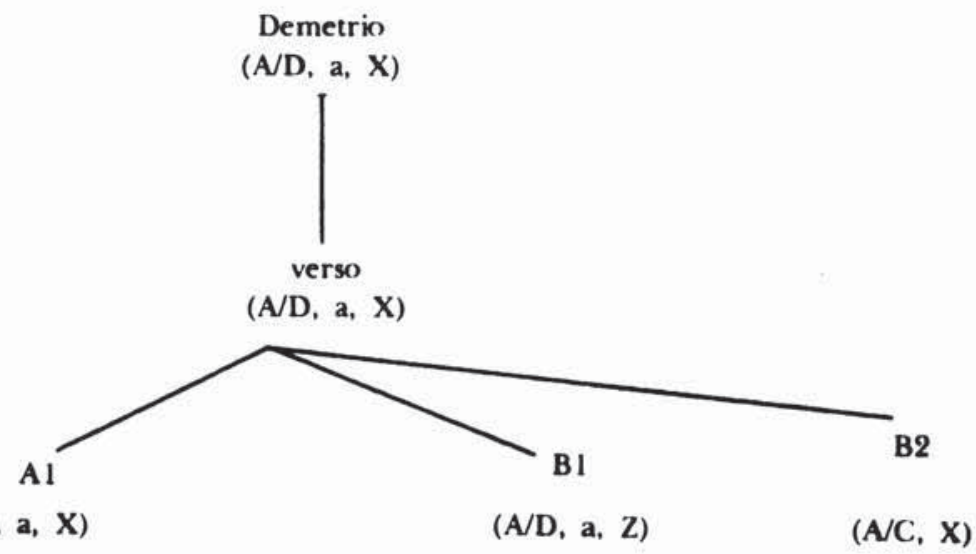

\section{La fábula de la rama de Fedro (Ph.) y del papiro de Michigan (M.-Y.)}

En el Fedro transmitido por nuestros manuscritos no aparece la fábula de la golondrina; pero sí está en la colección medieval llamada de Rómulo, derivada en parte de Fedro y varias de cuyas fábulas ausentes de éste se consideran habitualmente como derivadas de algunas del mismo que se han perdido. Son fábulas prosificadas, cuyo verso ha tratado de reconstruir Zander ${ }^{15}$. Damos a continuación la restitución por

\footnotetext{
${ }^{15}$ Phaedrus solutus, Lund 1921.
} 
Zander ${ }^{16}$ de la versión original, fedriana, de la fábula de la golondrina ${ }^{17}$.

\author{
Bonum consilium qui non audierit, malum \\ in sese inueniet; haec ut fabella approbat. \\ Spargi atque arari lini semen ceterae \\ aues uidere; <sed> pro nihilo hoc habuerunt. \\ Hirundo, <quo spectaret> hoc intelligens, \\ $<$ continuo> conuocatis auibus rettulit \\ hinc nasciturum cunctis magnum <auibus> malum. \\ $<A t>$ omnes dissimulantes <illam> riserunt. \\ Deinde ut fruticauit, <sic> hirundo iterum monet: \\ - Malum eruamus illud. Nam cum creuerit, \\ <laqueos> exinde <et torta> facient retia, \\ quibus artibus possimus humanis capi». \\ <At> omnes derrisere uerba hirundinis \\ consilium respuentes et contempserunt. \\ Quod illa ut uidit, sese ad homines transtulit \\ corum ut <semper> tuta sub tectis foret. \\ At quae respuerunt monita $\langle\mathrm{et}\rangle$ consilium illius, \\ cadunt <dolosa> semper <hominum> in retia.
}

En mi trabajo anterịor yo sostenía que esta fábula contaminaba el modelo de Al con el del lino, que yo entonces creía original del modelo de D. C.-A. Pero hemos visto que, desde entonces, hemos hallado ambos motivos juntos en M.-Y., fábula con restos de verso. En definitiva, se trata de un modelo muy antiguo, derivado de Demetrio pero con la introducción del tema del lino; un modelo que, hemos propuesto arriba, influyó en A2, también derivada de Demetrio, pero que utiliza el modelo del lino de una manera evidentemente secundaria.

Estas son las líneas generales. Pero falta que examinemos las diferencias entre Fedro y M.-Y. y que comparemos una y otra fábula con $\mathbf{R}$, A1 y A2. Esto es lo que vamos a hacer a continuación.

${ }^{10} \mathrm{Ob}$ cit., p. 63.

"La versión en prosa de Rómulo puede vere en Thiele, Der lateinische Aesop des Phaedrus und die Prosafassungen des Romulus, Heidelberg 1910, fáb. 124. En Les fabulistes latins de L. Hervieux, II, Paris 1894 (reimpresión de Olms, Heidesheim, 1970), pueden encontrarse diversas fábulas medievales idénticas o muy próximas a la de Rómulo, derivadas de ella: pp. 138 (fab. 20 del codex Ademari), 251 (18 de las Romuli breuiatae fabulae), 425 (19 del Romulus Vindobonensis), 462 (19 de las Vindobonae Romuleae fabulae), 483 (20 del Romulus Florentinus), 524 (19 del Romulus Nilantii, bastante variada), 577 (18 de Romuli Anglici cunctis... fabulae), 671 (16 de ex Romuli Nilantï... fabulae), 727 (1 18 de las ex Romulo " Nilantii... fabrulae nthmicae). De aquí ha salido una fábula prácticamente nueva en Romuli Anglici nonnullis, fab. 15 (= 656 p.). Sobre algunas variantes en Gualterio Anglico y Alexander Nequam, véase más abajo. 
Comparando la fábula de Fedro con la de M.-Y., que hemos recogido arriba, p. 194, y cuyo final está incompleto, vemos que son sensiblemente iguales.

Tenemos:

a) M.-Y., en la versión en prosa que conservamos al menos, versión con escasos restos de verso, es una versión abreviada. Le faltan elementos de Fedro que hallan claro paralelo en $A 1$ o en $R$ y que, por tanto, remontan a Demetrio. Cf. Ph. conuocatis auibus rettulit $=\mathrm{Al} \sigma u v \alpha-$

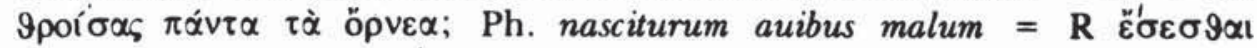

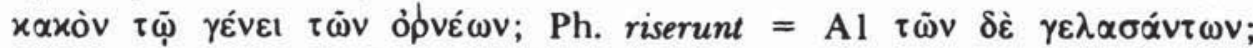
$\mathrm{Ph}$. omnes derrisere uerba hirundinis consilium respuentes et contempserunt $=\mathbf{R}$

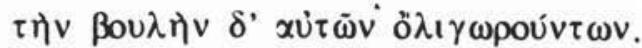

b) Alguno de estos elementos antiguos perdido secundariamente en M.-Y. está también en A2, sobre todo el tema de la asamblea de las aves. Con esta versión, que coincide con M.-Y. en el tema del lino pero lo varía (los pájaros perecen no por causa de las redes hechas con el lino, sino por engordar demasiado y ser cazados), hay, ya lo vimos, una

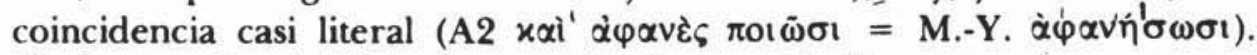
Nada extraño si A2 está contaminada por M.-Y.

c) Hay, sin embargo, una diferencia bastante sustancial entre las dos versiones. En M. - Y. la golondrina sugiere que los pájaros se coman las semillas de lino y esto es lo que hacen (con mal resultado) en A2. Pero en Fedro el consejo es arrancar el lino en cuanto brota: tema antiguo, derivado del de *arrancar el roble», ya lo dijimos. De la impresión de que el primer original que introdujo el tema del lino unía los dos consejos: primero comer las semillas, luego arrancar la planta. $\mathrm{Y}$ esto es exactamente lo que ocurre en la versión medieval de Gualterius Anglius (Walter el inglés) ${ }^{18}$. Me parece evidente que Rómulo, al extractar a Fedro, ha omitido un verso o dos: cuando dice a los pájaros que de la semilla del lino va a salir un gran mal para ellos, se abstiene de darles consejo alguno, como se esperaría. Antes del de arrancar las plantas de lino venía el consejo de comerse la semilla, que inspiró la variante de A2, ya desde época antigua.

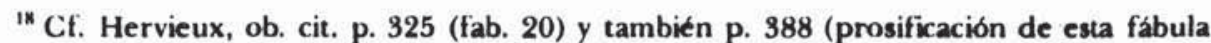
en disticos) y Alexander Nequam, ibid., p. 401 (fáb. 18).
} 
Ganamos así, en definitiva, un nuevo stemma parcial:

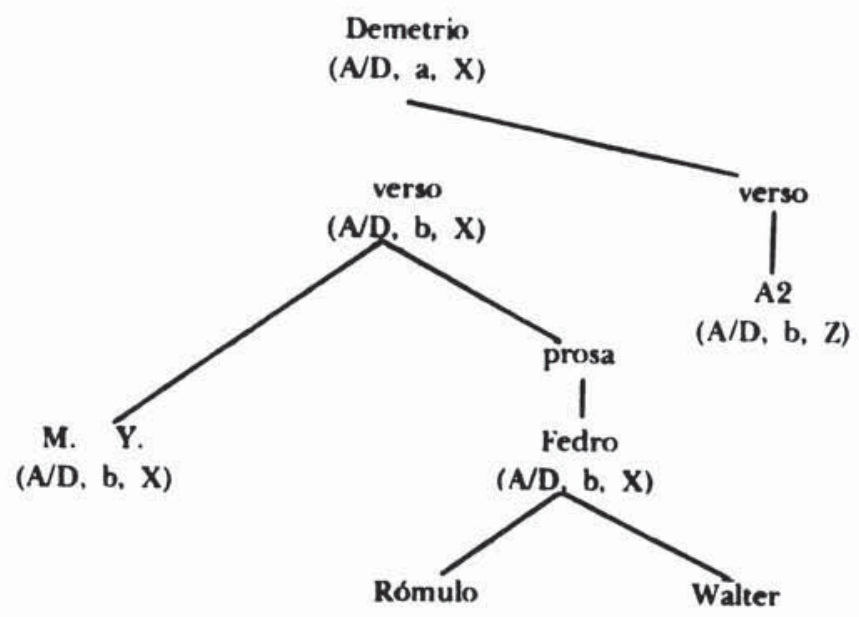

4. "El cazador y las aves"

Con esto no acaba la tradición derivada de nuestra fábula: en nuestra Edad Media y en la India aparecen fábulas de ella dependientes, creo, y hasta ahora no atendidas en este contexto.

Rómulo presenta como fábula 77 la del cazador y las aves, a la cual hay que añadir la versión del núm. 24 de las fábulas ex Romulo Nilantii ortae en Hervieux, II, p. 746. Sin duda deriva de la anterior. Basta, por tanto, con transcribir ésta, como hago a continuación (Rom. 2):

Sapientis consilium nullatenus praetermitti debere ammonet nos subiecta auctoris fabula.

In uerno aues diuersi generis dum exultarent et in nidis suis uelatae fronde sederent, aspiciunt aucupem lippum componere cannas suas et festucam inserere uisco. Illae ignarae et simplices aues sic inter se narrare coeperunt: «Quam pium hominem aspicimus, quia pro nimia bonitate lacrimae ex eius oculis profluunt, quotiens nos aspicit". De quibus una alès astutior et expertos habens omnes dolos aucupis sic dixisse fertur: *Heu, fugite simplices et innocentes aues et ab hac uos eripite fraude. Pro qua re moneo, ut impigres alarum pennis uos ad aerem liberum uolatu extollatis celeriter. Nam, si placet conoscere <uerum>, ad eius opera caute intendite et uidete, quia, quas fraude ceperit, mox morsu occisas aut praefocatas in cumbam reponit*.

Monet haec fabula, non dubium fieri posse, ab unius consilio multos de periculo liberari.

Ha desaparecido la golondrina: sólo nos quedan los pájaros y uno de ellos que, más inteligente, hace el papel de aquélla. Pero la derivación a 
partir de la fábula de la golondrina es clara, pues se trata de la caza de pájaros con liga y hay un ave inteligente que prevé el peligro (en Alexander Nequam se salva, mientras perecen las demás). Ha desaparecido, por supuesto, toda etiología. $\mathrm{Y}$ se ha añadido un rasgo: el cazador es legañoso y los pájaros creyeron al principio que lloraba de pura bondad.

Parece fácil, en sí, que una derivación como lésta se produjera a partir del modelo anterior: en la fábula 20 del codex Ademari hay un hombre que siembra el lino. Ahora bien, a partir de cualquier versión en que se habla, sea de liga, sea de lino, puede deducirse otra en que interviene el cazador que pone la liga o las redes. $\mathrm{Y}$ aquí se habla de liga: luego la fábula de Rómulo está emparentada bien con $\mathbf{R}$, bien con A1. En $\mathbf{R}$ encontramos ya, en realidad, el tema del cazador y no es improbable que estuviera incluso en Demetrio. Naturalmente, la fábula de Rómulo está tan alterada que no es posible ver si viene de $\mathbf{R}$ o de Al o directamente de Demetrio.

En todo caso, no es dudoso que tiene tradición antigua. No parece presentar huella de verso: luego no es de Fedro, salvo que el verso esté tan alterado que sea irreconocible. Ahora bien, es sabido que en Rómulo junto a las fábulas derivadas de Fedro hay otras de tradición antigua que, en ocasiones, sólo a través de esta fuente nos han llegado. Entre ellas hay algunas que, en cambio, han encontrado un camino para llegar al Pañcatantra, en la India ${ }^{19}$.

Pienso que Rómulo recoge en este caso una fábula griega derivada en definitiva de Demetrio: no podemos saber si de una colección versificada o no. Y una prueba ulterior de ello es que la fábula en cuestión halla un derivado que creo claro en una fábula india del Tanträkhyäyika y el Peñcatantra, que he hecho ver en mi libro que dependen en buena medida de fábulas griegas, y concretamente de fábulas griegas de colecciones prosificadas del s. Il a. C., en parte diferentes de las conservadas ${ }^{20}$. Este sería un caso más. Aunque el detalle merece ser investigado más despacio.

Doy, en primer término, un resumen de la fábula india (Tantränkhyäyika III 11, „El viejo cisne como salvador») ${ }^{21}$.

\footnotetext{
19 Cf. Historia... p. 140 ss. Es Nфjgaard, La Fable Antique II, p. 404 ss., quien ha relacionado Rómulo 39. «El campesino y la serpiente* con Pañcatantra III 6; mi hipótesis de que el origen está en una fábula griega se apoya en mi estudio, en el libro mencionado, sobre la relación entre la fábula griega y la india en general.

${ }^{20}$ Cf. Historia..., p. 699.

${ }^{21}$ Cf. la edición de Herter, Tanträhloyäyika II, Leipzig y Berlín 1909, p. 138 s., donde se da el texto traducido.
} 
En un elevado árbol vivía una familia de cisnes ${ }^{22}$. Un cazador se sentó un día junto a él, cansado de sus vanos intentos de cazar. $Y$ quedó sorprendido por la presencia de los cisnes, ideando un medio para apoderarse de ellos: sembrar al pie del árbol plantas trepadoras, para subir luego por ellas. Así hizo, y viéndolas crecer. un viejo cisne aconsejó a los cisnes que las arrancaran. Pero ellos despreciaron su consejo. Las plantas crecieron y el cazador subió al árbol y puso su red, en la que quedaron aprisionados los cisnes. El viejo cisne oyó su clamor y tras hacerles reproches atendió a su petición de ayuda. Les dijo que se hicieran los muertos y, cuando el cazador les arrojara al suelo, salieran volando. Así se salvaron.

Junto a elementos claramente indios (el cisne o hamsah propio de tantas leyendas, la planta trepadora), son fácilmente reconocibles rasgos de las fábulas griegas que estudiamos. El cazador que tiende la trampa a las aves es sin duda el mismo de Rom. 2, que acabamos de ver, aunque dijimos que se encontraba presente ya en $R$. Tanto en Rom. 2 como en la fábula india hallamos un final feliz. Pero el consejo de arrancar la planta trepadora recuerda el de arrancar el lino, que hemos hecho remontar a la fuente común de M.-Y. y Fedro; se habla en la fábula india, de otra parte, de "red». Resulta, entonces, que la fábula india deriva de una doble fuente griega: una próxima a Fedro y otra que es el modelo de Rom. 2 (salvo que ambos temas aparecieran, conjuntamente, en una fábula griega perdida). Sea una fuente, sean dos, parece verosímíl llevarlas a fecha helenística, concretamente, al s. II a. C., que es cuando, según he propuesto en otro lugar ya citado, la fábula griega de colecciones ya prosificadas y sin promitios ni epimitios sistemáticos, fábula organizada en colecciones parcialmente diferentes de las que han llegado directa o indirectamente a nosotros, influye en la India.

La hipótesis de que la fábula india sea original y haya influido en la griega (como propone $\mathrm{N} \phi$ gaard para el caso de la fábula de la serpiente, creo que erróneamente), no es sostenible. Pues está aislada en la India, mientras que en Grecia hay, como hemos dicho, una amplia tradición. Es fácil de explicar la indianización; en cambio, de la fábula india no podrían salir las fábulas griegas. En cuanto al tema del cazador como hombre malvado, es muy indio, ciertamente: pero tampoco falta en Grecia, como acabamos de ver.

\section{CONCLUSIONES}

El estudio de las 15 versiones fundamentales conservadas (y algunas más perdidas, reconstruidas más o menos completamente) de la fábula

\footnotetext{
22 Traducción usual, nada exacta, de hamsah.
} 
de la golondrina y los pájaros, con sus diversas variantes, nos lleva a algunas conclusiones que creemos de interés. Una fábula tan bien $\rightarrow \tan$ excepcionalmente bien - transmitida no podía dejar de arrojar luz sobre la transmisión de la fábula antigua. Las principales concusiones podrían ser las siguientes:

1. Influencia de los temas míticos y religiosos relacionados con el mundo animal y vegetal tanto en la gestación de la fábula como en su evolución. Me refiero a temas como el de la causa del comportamiento animal, que deriva de hechos míticos del origen de los tiempos; el del carácter sagrado de la golondrina y su culto en palacios y casas, donde es acogida en su migración anual; el de las cualidades adivinatorias y la inteligencia atribuidas a la lechuza; el del mito de Filomela y Procne.

2. Carácter unitario de la tradición fabulística: todo parece remontar a Demetrio de Falero.

3. Carácter múltiple de las versificaciones de la fábula de Demetrio, que permitían libertades temáticas (cambio de ave, motivos, etiología). Escalonamiento de esas versificaciones (la previa a A2 presupone la que está en la base de M.-Y. y Fedro).

4. Complejidad de la ramificación a partir dēesas versificaciones. Existencia de contaminaciones.

5. Posibilidad de dos versiones en diversos manuscritos de la Augustana y de dos versiones, también, en la tradición babriana. En estos casos hay una de texto muy conservador y otra fuertemente innovada (por atender a un mito o a un tema cínico, etc.)

6. Importancia de la tradición medieval occidental para reconstruir fábulas perdidas de Fedro y otras derivadas de Demetrio y no testimoniadas fuera de allí. No sólo Rómulo es importante, hay que comparar otras versiones más.

7. Influjo de la tradición griega en la India, que incluso contamina, parece, dos fábulas diferentes, aunque emparentadas.

Estas consecuencias y la red de relaciones en general dentro de la tradición de la fábula estudiada, pueden quizá verse más claramente en el stemma que acompañamos, que resume los anteriores.

FRANCISCO R. ADRADOS 


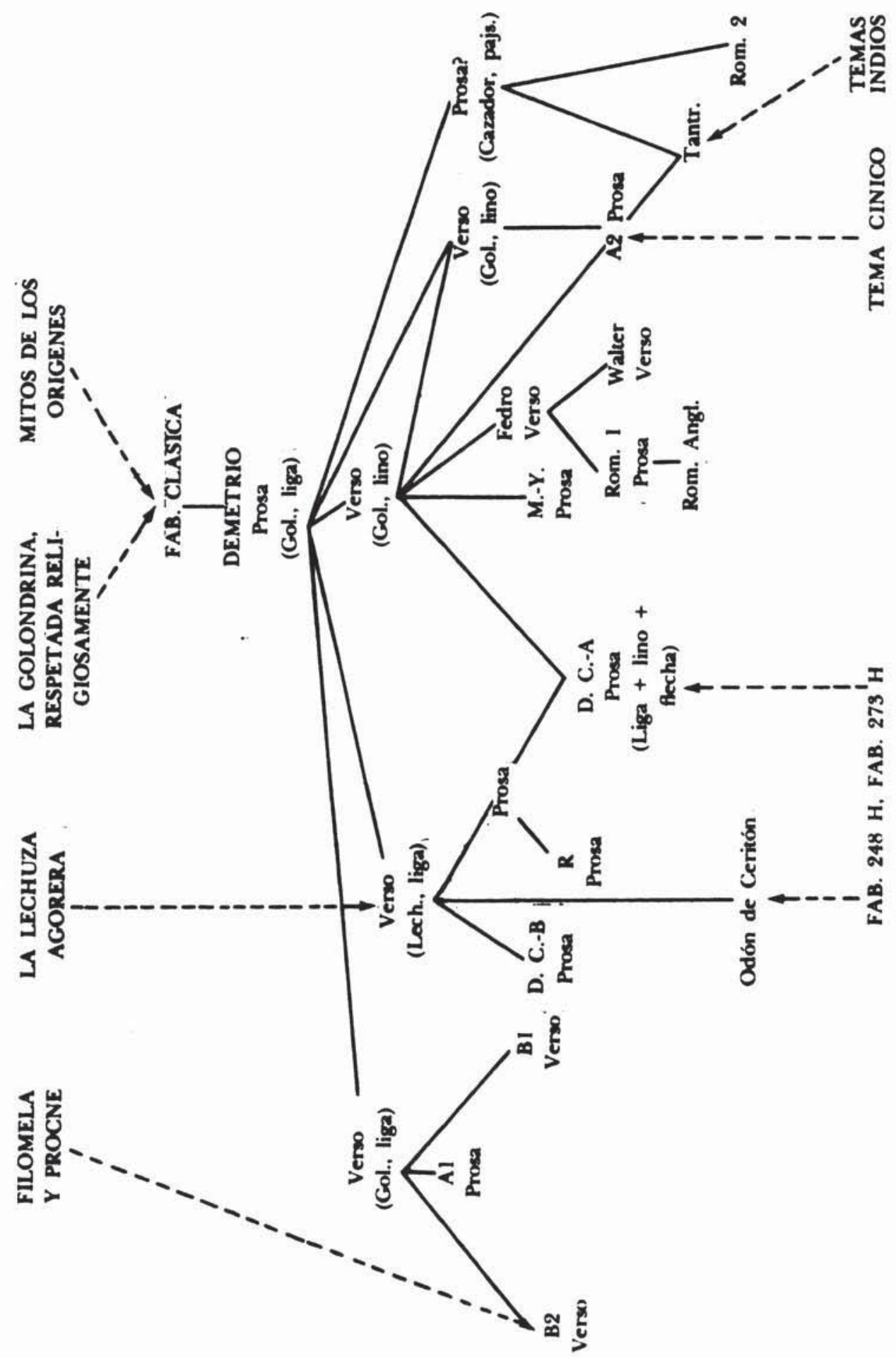

